\title{
Previsão da demanda brasileira de biodiesel utilizando redes neurais artificiais
}

\author{
Forecasting the Brazilian demand for biodiesel using artificial neural networks \\ Pronóstico de la demanda brasileña de biodiésel mediante redes neuronales artificiales
}

Recebido: 27/02/2021 | Revisado: 06/03/2021 | Aceito: 19/04/2021 | Publicado: 02/05/2021

\author{
Kaique Vitor Louzada Caires \\ https://orcid.org/0000-0002-3467-2310 \\ Universidade Federal da Bahia, Brasil \\ E-mail: kaiquevitor16@hotmail.com \\ George Simonelli \\ https://orcid.org/0000-0002-8031-1401 \\ Universidade Federal da Bahia, Brasil \\ E-mail: gsimonelli@ufba.br
}

\begin{abstract}
Resumo
O biodiesel é um combustível renovável utilizado como uma alternativa para substituir de modo total ou parcial o diesel de petróleo. A porcentagem obrigatória desse biocombustível adicionado ao diesel fóssil no Brasil tem sido elevada constantemente. Prever a quantidade de biodiesel que será demandada futuramente é essencial para manter o balanço nacional superavitário e auxiliar nas tomadas de decisões do setor. As redes neurais artificiais (RNAs) são úteis para previsão de diferentes tipos de demandas. Assim sendo, esse estudo utiliza redes neurais artificiais na previsão da demanda brasileira de biodiesel. A RNA proposta neste trabalho englobou dados obtidos de um modelo não-paramétrico de previsão de demanda baseado em séries temporais. O modelo não-paramétrico considerou as tendências e sazonalidade dos dados para previsão da demanda de biodiesel. Foram modeladas 100 redes do tipo perceptron multicamadas com retropropagação do erro para dois cenários do biodiesel brasileiro (uso de 15\% (B15) ou 20\% (B20) de biodiesel ao diesel). Todos os valores de $\mathrm{R}^{2}$ maiores que 0,99 para as redes simuladas e RMSE $<2 \%$ comprovam que o modelo de RNA desenvolvido possui alta precisão em prever a demanda de biodiesel. A melhor rede para cada cenário foi determinada por análise heurística do RMSE. Os resultados das melhores RNA's simuladas mostraram um crescimento da demanda de biodiesel de 2019 a 2050 de 150,63\% para o B15, e de 229,73\% para o B20. Ambos cenários de aumento de demanda são justificados pela elevação gradual da porcentagem obrigatória do biodiesel ao diesel. Dessa forma, os resultados crescentes da demanda de biodiesel comprovam a busca do país por um combustível não-tóxico, biodegradável e renovável na sua matriz energética.
\end{abstract}

Palavras-chave: Biodiesel; Brasil; Redes neurais artificiais; Sazonalidade; Previsão de demanda.

\begin{abstract}
Biodiesel is a renewable fuel used as an alternative to totally or partially replace petroleum diesel. The mandatory percentage of this biofuel added to fossil diesel in Brazil has constantly been increasing. Predicting the amount of biodiesel that will be demanded in the future is essential to maintain the national surplus balance and assist in the sector decision-making. Artificial neural networks (ANNs) help forecast different types of demands. Therefore, this study uses artificial neural networks to forecast the Brazilian demand for biodiesel. The ANN proposed in this work encompassed data obtained from a non-parametric demand forecasting model based on time series. The nonparametric model considered the trends and seasonality of the data to forecast the demand for biodiesel. One hundred multilayer perceptron networks were modeled with error propagation for two scenarios of Brazilian biodiesel (use of $15 \%$ (B15) or 20\% (B20) of biodiesel to diesel). All values of R2 greater than 0.99 for the simulated networks and RMSE $<2 \%$ prove that the RNA model developed has high precision in predicting the demand for biodiesel. The best network for each scenario was determined by RMSE heuristic analysis. The best-simulated RNA results showed growth in biodiesel demand from 2019 to 2050 of $150.63 \%$ for B15. And $229.73 \%$ for B20. Both demand growth scenarios are justified by the gradual increase in the mandatory percentage of biodiesel to diesel. Thus, the growing results of biodiesel demand prove the country search for a non-toxic, biodegradable, and renewable fuel in its energy matrix.
\end{abstract}

Keywords: Biodiesel; Brazil; Artificial neural networks; Seasonality; Demand forecast.

\section{Resumen}

El biodiésel es un combustible renovable que se utiliza como alternativa para sustituir total o parcialmente el diésel de petróleo. El porcentaje obligatorio de este biocombustible agregado al diesel fósil en Brasil ha aumentado constantemente. Predecir la cantidad de biodiésel que se demandará en el futuro es fundamental para mantener el saldo excedentario nacional y ayudar en la toma de decisiones del sector. Las redes neuronales artificiales (ANN) son útiles para pronosticar diferentes tipos de demandas. Por lo tanto, este estudio utiliza redes neuronales artificiales para 
pronosticar la demanda brasileña de biodiesel. La ANN propuesta en este trabajo abarcó datos obtenidos de un modelo de pronóstico de demanda no paramétrico basado en series de tiempo. El modelo no paramétrico consideró las tendencias y la estacionalidad de los datos para pronosticar la demanda de biodiesel. Se modelaron 100 redes de perceptrones multicapa con propagación de errores para dos escenarios de biodiesel brasileño (uso de 15\% (B15) o $20 \%$ (B20) de biodiesel a diesel). Todos los valores de R2 superiores a 0,99 para las redes simuladas y RMSE <2\% demuestran que el modelo de ARN desarrollado tiene una alta precisión en la predicción de la demanda de biodiésel. La mejor red para cada escenario se determinó mediante análisis heurístico de RMSE. Los resultados de los mejores ARN simulados mostraron un crecimiento en la demanda de biodiésel de 2019 a 2050 de 150,63\% para B15 y $229,73 \%$ para B20. Ambos escenarios de crecimiento de la demanda se justifican por el aumento gradual del porcentaje obligatorio de biodiésel a diésel. Así, los crecientes resultados de la demanda de biodiesel evidencian la búsqueda del país de un combustible no tóxico, biodegradable y renovable en su matriz energética.

Palabras clave: Biodiésel; Brasil; Redes neuronales artificiales; Estacionalidad; Previsión de demanda.

\section{Introdução}

$\mathrm{O}$ mundo anseia por fontes alternativas de energia. $\mathrm{O}$ risco de esgotamento dos combustíveis fósseis em um futuro próximo, assim como o aumento dos problemas socioeconômicos relacionados ao meio ambiente levaram a busca e o desenvolvimento de combustíveis sustentáveis a partir de fontes renováveis, baratas e ecológicas (Chidambaranathan, et al., 2020). Dessa forma, tem havido um interesse crescente em combustíveis alternativos, como o biodiesel, para aplicações em motores a diesel. Atualmente, vários países enfatizam e estimulam o uso do biodiesel por vias governamentais e regulatórias, por meio de incentivos e necessidades volumétricas prescritivas (Singh, et al., 2020).

Alinhado com os objetivos mundiais em explorar os biocombustíveis que podem superar a escassez e a dependência de combustíveis fósseis, o Brasil, evoluiu gradativamente o percentual de biodiesel presente no diesel fóssil de $2 \%$ em janeiro de 2008 até chegar nos atuais 12\%. Mas a Resolução no 16 do Conselho Nacional de Política Energética (CNPE), de 29 de outubro de 2018, autorizou a elevação do percentual de biodiesel na mistura com o diesel, de $1 \%$ ao ano a partir de $1^{\circ}$ de junho de 2019, até o patamar de 15\% em 2023 (Conselho Nacional de Política Energética, 2018). Assim, o biodiesel já é uma realidade no Brasil e garante uma posição destacada em relação ao resto do mundo, fortalecendo sua imagem como um país que valoriza a diversidade de fontes energéticas (Agência Nacional de Petróleo, Gás Natural e Biocombustível, 2020).

Conhecer a demanda futura do biodiesel no Brasil é necessário para auxiliar nas tomadas de decisões do setor. O conhecimento da demanda futura auxilia na criação de estratégias para assegurar a disponibilidade das matérias-primas necessárias ao processo de produção deste biocombustível. Além disso, é importante para mensurar a diminuição das emissões de $\mathrm{CO}_{2}$ relacionadas ao aumento do consumo deste combustível no país. Prever qual a quantidade de biodiesel será demandada futuramente é essencial para manter o balanço nacional superavitário, de forma a evitar déficit na capacidade de produção e assegurar a viabilidade de investimentos em plantas de processamento de biodiesel por parte do governo brasileiro.

As redes neurais artificiais (RNAs) são úteis na previsão de demanda devido à sua capacidade de acomodar dados não lineares, para capturar relacionamentos funcionais sutis entre dados empíricos, mesmo quando eles são desconhecidos ou difíceis de descrever (Kochak \& Sharma, 2015). Uma das principais áreas de aplicação das RNAs é a previsão (Zhang, et al., 1998) e numerosas pesquisas estão sendo desenvolvidas nesse campo. Katsatos \& Moustris (2019) aplicaram redes neurais para previsão do consumo de energia em Atenas, na Grécia. No estudo de Karunathilake \& Nagahamulla (2017), a RNA é utilizada na previsão diária da demanda de eletricidade do Sri Lanka. O artigo de Gupta \& Nigam (2020) apresenta o uso da RNA para previsão do preço do petróleo. Em alguns locais do Reino da Arábia Saudita (Brahimi, et al., 2019), a velocidade diária do vento é prevista por meio da RNA. O artigo de Acheampong \& Boateng (2019) aplica uma RNA para desenvolver modelos para prever a intensidade de emissão de carbono na Austrália, Brasil, China, Índia e EUA.

Nessa pesquisa, junto com a RNA é utilizado um modelo não-paramétrico de previsão de demanda visando obter o conjunto de dados de entrada e saída necessários para estimar a demanda de biodiesel no Brasil. Esse modelo se baseia numa análise numérica de dados passados para projeção da demanda futura, considerando a sazonalidade e a tendência que eles 
possam ter (Tubino, 2007). A utilização do modelo não-paramétrico com ajuste de séries temporais para variação sazonal é feita para a remoção da sazonalidade da série para depois estudá-la em seus demais aspectos, uma vez que a existência de movimentos sazonais afeta o reconhecimento e a interpretação de importantes movimentos não-sazonais numa série (Queiroz \& Cavalheiro, 2003).

A associação da RNA com um modelo de previsão de demanda não-paramétrico baseado em séries temporais com eventuais tendências e sazonalidade dos dados permitiu estimar a demanda de biodiesel no Brasil até o ano de 2050, objetivo deste estudo. Tal como ocorre para outras fontes de energia, a previsão da demanda por biodiesel é fundamental. O modelo obtido tem potencial para ser aplicado na análise das demandas do biodiesel no futuro através da modificação dos indicadoreschave utilizados, simulando diferentes cenários políticos para o uso desse biocombustível como uma substituição apropriada e sustentável para o motor a diesel devido à sua natureza renovável, não-tóxica e ecológica.

\section{Metodologia}

\subsection{Estrutura da rede neural}

Embora existam vários tipos de RNAs, nesta pesquisa, um modelo de rede neural conhecido como perceptron de múltiplas camadas (MLP) foi usado. A MLP é o modelo de redes neurais mais amplamente utilizado para previsões (Ebrahimabadi, et al., 2015). Sua estrutura consiste em uma camada de entrada, uma ou mais camadas ocultas e uma camada de saída.

O MLP é uma técnica de aprendizado supervisionado que compara as respostas fornecidas pela rede neural com as respostas desejadas, corrigindo os pesos da rede de acordo com o erro verificado (Sivamani, et al., 2019). O algoritmo mais popular e usado nesse estudo para correção dos pesos é o de retropropagação. Primeiro, o sinal se propaga para frente, a partir da camada de entrada através da camada oculta até a camada de saída. Em seguida, o erro entre a saída da RNA e a saída desejada é calculado e propagado para trás passando da camada de saída para a camada oculta e, em seguida, para a camada de entrada. A rede neural atinge os pesos ideais após o processo de treinamento iterativo para reduzir o erro ao nível desejado (Ling, et al., 2020).

As principais vantagens que incentivaram o uso da MLP com retroprogação foram: a) rede de solução pequena e velocidade computacional rápida que permite o treinamento em grandes conjuntos de dados de entrada; b) generalização automática de conhecimento, permitindo o reconhecimento de conjuntos de dados; c) robustez para reconhecer dados ocultos por ruído; d) minimização da raiz do erro quadrático médio em todos os conjuntos de dados de treinamento e) treinamento supervisionado (Ekonomou, 2010).

\subsection{Arquitetura da rede neural}

A grande desvantagem dos MLPs com retropropagação são as muitas variáveis que devem ser consideradas na sua construção, como o algoritmo de aprendizado de retropropagação, o tipo de função de transferência, o número de camadas ocultas e o número de neurônios das camadas ocultas (Ekonomou, 2010). Os parâmetros da RNA usados para estimar a demanda de biodiesel no Brasil são apresentados no quadro 1. 
Quadro 1 - Variáveis utilizadas para estimar a demanda de biodiesel no Brasil.

\begin{tabular}{|c|c|}
\hline Propriedade & Valor \\
\hline Algoritmo & Retropropagação de Levenberg-Marquardt \\
\hline Função de transferência & Sigmóide tangente hiperbólica (tansig) \\
\hline Número de camada(s) oculta(s) & 1 \\
\hline Número de neurônios na camada oculta & 2 \\
\hline
\end{tabular}

Fonte: Autores.

O número de camada(s) oculta(s) e neurônios dela(s) deve ser reduzido ao mínimo em que se obtém um valor da raiz do erro quadrático médio (RMSE) menor que 2\%. Isso ocorreu com 1 camada oculta e 2 neurônios nela (Figura 1). Assim sendo, essa estrutura de rede neural foi escolhida.

Figura 1 - RNA utilizada para estimar a demanda de biodiesel no Brasil.

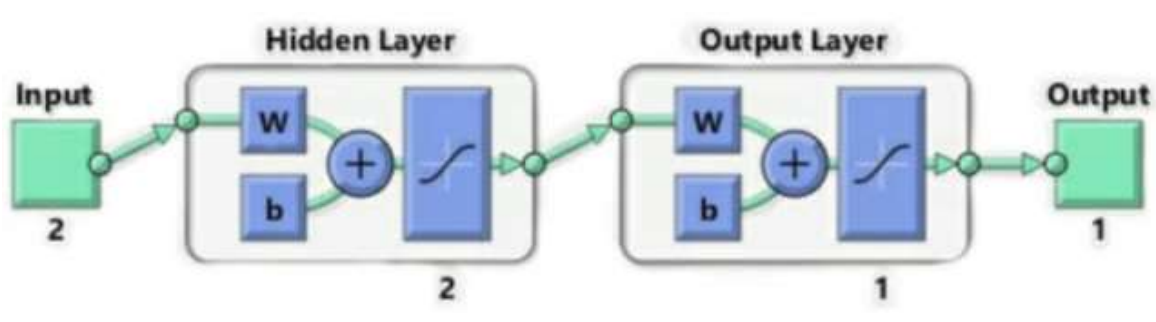

Fonte: Autores.

As funções de transferências mais usadas em redes neurais artificiais são as funções sigmóide tangente (tansig), sigmóide logarítmica (logsig) e funções de transferência linear (purelin). A função de transferência tansig tem melhor desempenho de previsão e por isso foi utilizada neste estudo (Turp, et al., 2011). Escolheu-se o algoritmo de retropropagação de Levenberg-Marquardt no processo de treinamento, já que ele pode atingir o maior $\mathrm{R}^{2}$ e menores erros médios quadráticos em comparação com qualquer outro algoritmo (Farobie, et al., 2015).

\subsection{Variáveis de entrada e saída da rede neural}

Para estimar a demanda de biodiesel no Brasil foram utilizadas duas variáveis independentes:

1- Nível legal obrigatório para a mistura do biodiesel ao diesel.

2- Vendas de óleo diesel tipo B (que possui adição de biodiesel).

A escolha dessas duas variáveis está relacionada ao fato de que o mercado potencial para o biodiesel é determinado pelo mercado de diesel. Além disso, a demanda de biodiesel depende dos percentuais mínimos obrigatórios da adição desse biocombustível ao óleo diesel vendido aos consumidores finais para uso em motores a combustão interna. O biodiesel está atrelado à demanda por óleo diesel, de forma que, para cada litro de diesel vendido, atualmente, a adição de 12\% de biodiesel (B12) é obrigatória, definindo o tamanho do mercado brasileiro.

Foram coletados dados da mistura obrigatória de biodiesel ao diesel, vendas de diesel B e produção mensal de biodiesel nos períodos de 2005 a 2019 na Agência Nacional de Petróleo, Gás Natural e Biocombustíveis (ANP). Assim sendo, utilizamos os documentos da ANP como instrumentos de coleta de dados (Pereira, et al., 2018). O período usado deve-se a inexistência de dados da produção mensal de biodiesel anteriores à lei de 2005 que introduziu o biodiesel na matriz energética 
brasileira.

Atualmente, o percentual obrigatório de biodiesel presente no diesel fóssil no Brasil é de 12\%. Visando diferentes análises de estimativa da demanda de biodiesel no Brasil, foram considerados dois cenários: (i) elevação do percentual de biodiesel na mistura de $1 \%$ ao ano até o patamar de 15\% (B15) em 2023, como definido pela Resolução CNPE $n^{\circ}$ 16, de 29 de outubro de 2018 (15\% foi mantido constante até 2050); e (ii) elevação do percentual de biodiesel na mistura, de $1 \%$ ao ano até o patamar de 20\% (B20) em 2028, como definido pelo Projeto de lei (PL) 528/2020 protocolado (e, em tramitação) na Câmara dos deputados do Brasil (20\% foi mantido constante até 2050).

Como o MLP é uma técnica de aprendizado supervisionado que compara as respostas de saída com as respostas desejadas, nós fornecemos para a rede pares das entradas e saídas para o período de 2005 a 2050. De 2005 a 2019 os dados estavam disponíveis na ANP. De 2020 a 2050 usamos um modelo não paramétrico de decomposição de séries temporais que se baseia na demanda do passado para projetar a demanda futura.

Como a produção mensal de biodiesel não tem comportamento livre por estar atrelada às imposições do governo, nós utilizamos os dados das vendas de diesel B para fazer a previsão da demanda de biodiesel (Carmo, et al., 2009). Foi aplicado o modelo de previsão de demanda da média móvel centrada (MMC). Nele, levou-se em consideração a tendência dos dados (crescimento das vendas de diesel B no período analisado (Figura 2)) e a sazonalidade (observada com uma queda das vendas nos meses finais e crescimento nos meses iniciais dos anos de 2005 a 2019) (Figura 3). A primeira etapa para a realização da previsão é a definição dos ciclos. Cada ciclo deve ter um comportamento semelhante. Para os dados analisados das vendas de diesel B, nós utilizamos que os ciclos coincidem com a escala de tempo anual.

Figura 2 - Vendas de diesel B no Brasil de 2005-2019.

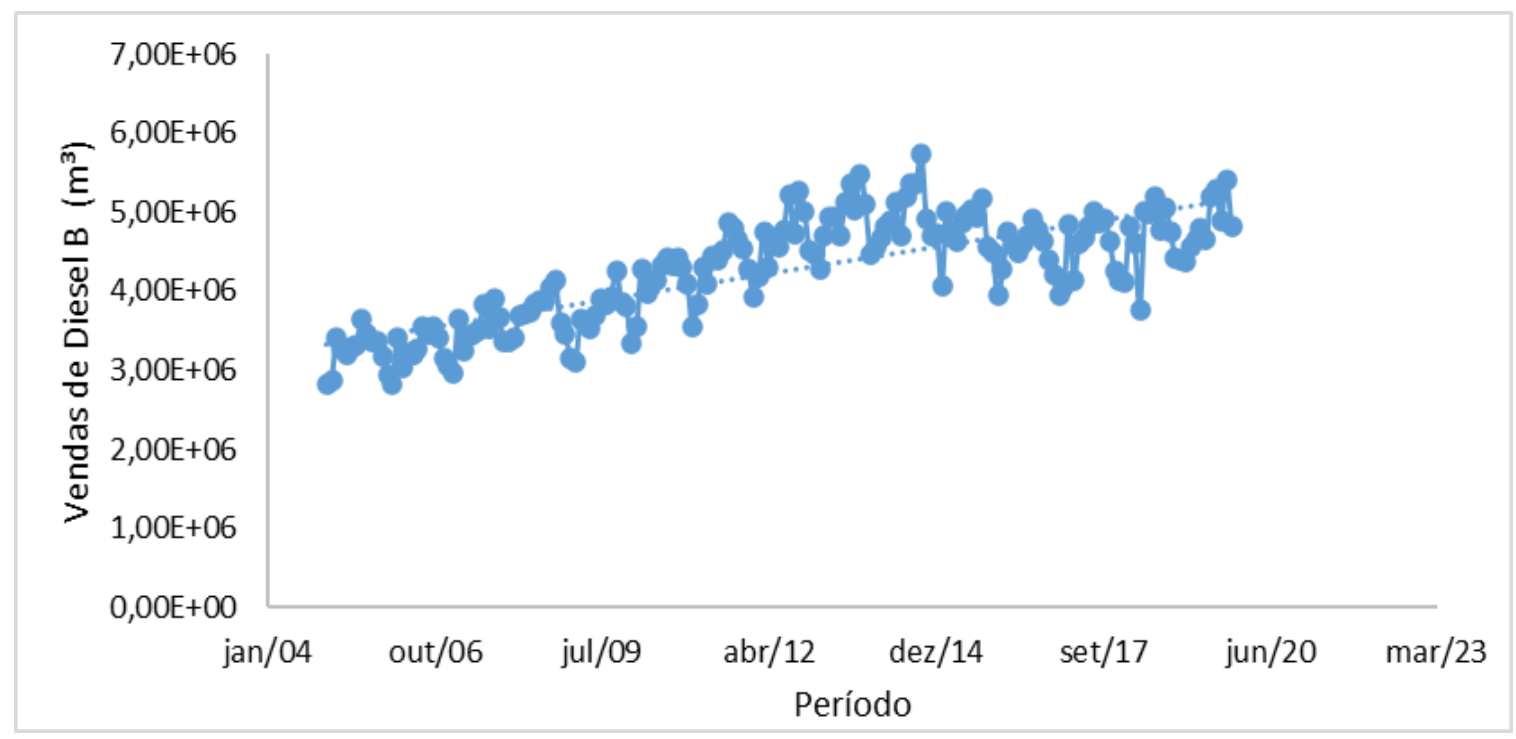

Fonte: Autores, a partir dos dados da ANP. 
Figura 3 - Comportamento mensal das vendas de diesel B no Brasil de 2005 a 2019.

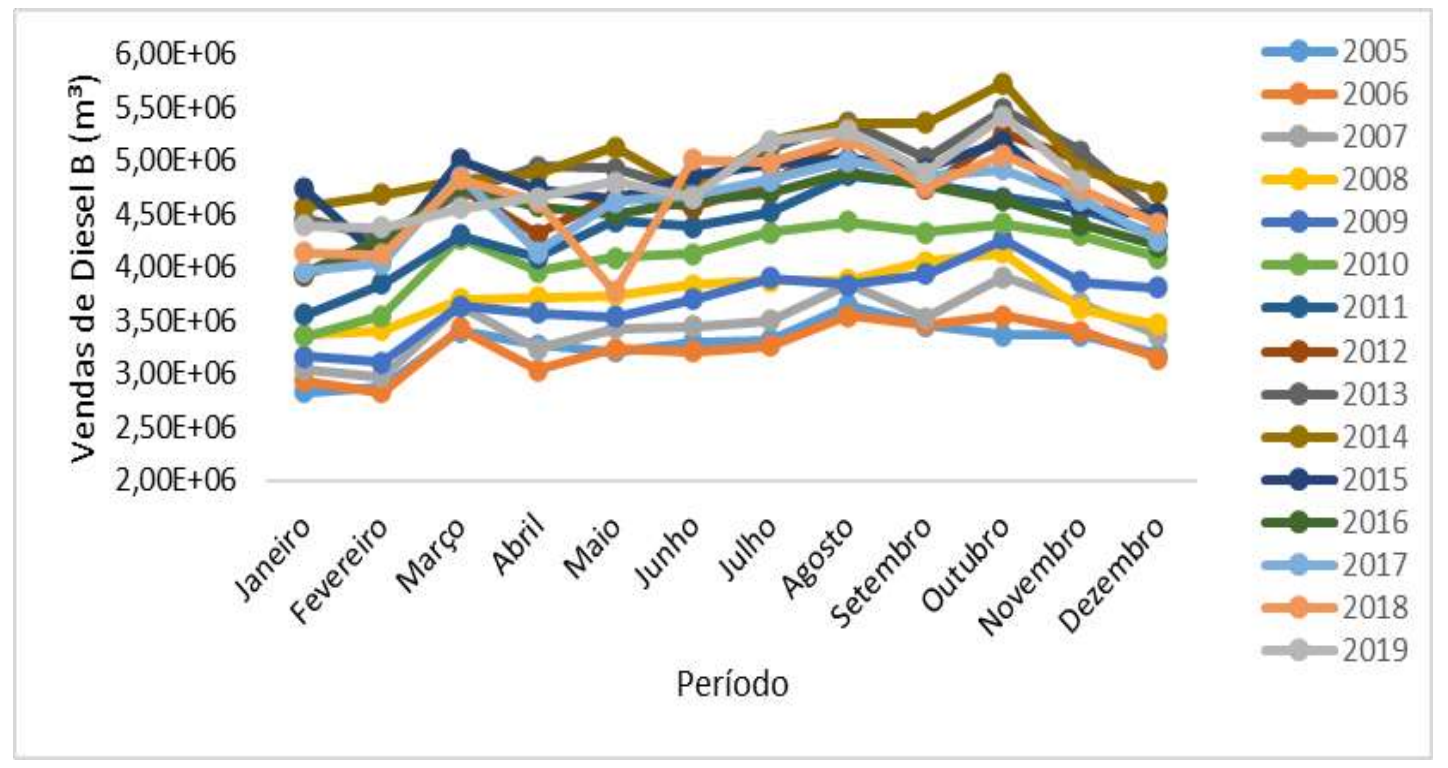

Fonte: Autores, a partir dos dados da ANP.

A partir da demanda real de cada um dos ciclos é estimada a demanda média móvel. Sendo o ciclo composto por um número par, com o centro dos dados no meio de um período, primeiro, se calcula a média móvel centrada no meio dos períodos $\left(\mathrm{MMC}^{\prime}\right)$. No estudo de caso analisado, a média móvel centrada está localizada entre os meses de junho e julho, e esta média é dada pela média dos seis períodos anteriores (janeiro a junho) e dos seis períodos posteriores:

$$
M M C^{\prime}=\frac{\text { DemandaDiesel JANEWE }^{+\ldots}+\text { Demand a Diesel }_{\text {DEZEMBEO }}}{12}
$$

Foi calculada a média destas intercalações, que resultou na média móvel centrada do período (MMC):

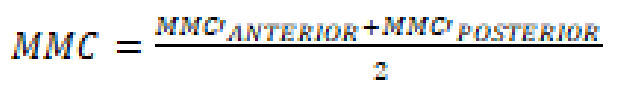

Em seguida, são obtidos os índices de sazonalidade do período:

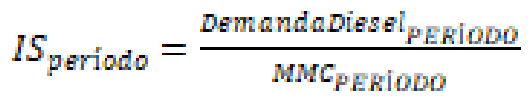

Com o IS de cada período são calculados os índices de sazonalidade médios para cada mês, que é a média dos índices de sazonalidade de cada mês dos anos da série histórica. Foi retirada a sazonalidade da série de dados históricos dividindo-se a demanda de diesel B do período pelo seu Índice de Sazonalidade Médio correspondente. Posteriormente, a partir da demanda do período, livre dos ciclos de sazonalidade, é obtida a equação da reta através de regressão dos dados das vendas de Diesel B (Y) em função do período analisado $(\mathrm{X})$ para verificar a tendência dos dados:

$$
\mathrm{Y}=3,35 * 10^{6}+9971,86 * \mathrm{X}
$$

A partir da Equação da Tendência obtida é calculada a previsão dos dados históricos para o próximo período. Por fim, são aplicados os índices de sazonalidade sobre a previsão, multiplicando-se a demanda tendencial prevista de cada período por seu índice de sazonalidade médio correspondente. Com o modelo de previsão das vendas de diesel B e a partir da porcentagem 
obrigatória de biodiesel ao diesel em cada cenário (B15 e B20) foram calculados os valores mensais da demanda de biodiesel até o ano de 2050. Através do somatório dos resultados mensais, obteve-se os resultados anuais.

\subsection{Pré-tratamento das variáveis de entrada e saída da rede neural}

O treinamento da rede neural é mais eficiente executando etapas de pré-tratamento nas variáveis de entrada e saída. Com todos os pares das entradas e saída da rede neural de 2005 a 2050, antes de exportar os dados para a RNA eles foram normalizados. O processo de normalização tem grande efeito na preparação dos dados para serem adequados ao treinamento (Jayalakshmi \& Santhakumaran, 2011).

Se eles forem alimentados diretamente à rede, como padrões de treinamento, variáveis de entrada com valor mais alto podem tender a suprimir a influência de outras menores. Além disso, existe o risco de os neurônios simulados atingirem as condições saturadas. Se os neurônios ficarem saturados, as alterações no valor de entrada produzirão uma alteração muito pequena ou nenhuma alteração no valor de saída. Isso afeta o treinamento da rede (Rajakarunakaran, et al., 2008). Portanto, os dados são normalizados antes de serem apresentados à rede neural, de modo que a RNA dê prioridade igual a todas as entradas. A normalização de dados compactou o intervalo de dados de treinamento entre 0 e 1 , devido a utilização da função de transferência sigmóide tangente hiperbólica. Para a normalização empregou-se:

$$
\text { Variável normalizada }=\left(x-X_{\min }\right) /\left(X_{\operatorname{máx}}-X_{\min }\right)
$$

Onde x é o valor a ser normalizado, $X_{\operatorname{minn}}$ e $X_{m a ́ x}$ são os valores mínimos e máximos de cada variável, respectivamente.

\subsection{Modelagem e simulação das redes neurais}

A rede neural criada consiste em duas entradas, com uma camada oculta e uma camada de saída. A função de ativação na camada oculta e na camada de saída é a sigmóide tangente hiperbólica (tansig). O algoritmo de retropropagação de Levenberg-Marquardt é encarregado pelo processo de treinamento.

Com a estrutura e arquitetura da rede definida foram feitas 50 simulações para cada cenário analisado. Setenta por cento dos dados foram escolhidos para o treinamento da RNA, 15\% para testar a RNA treinada e 15\% para validar a estimativa final da demanda de biodiesel pela RNA desenvolvida. A forma randômica de selecionar os dados de treinamento, teste e validação diferenciava cada simulação feita para os cenários B15 e B20.

O desempenho da RNA foi avaliado com base no coeficiente de correlação $\left(\mathrm{R}^{2}\right)$ e na raiz do erro quadrático médio (RMSE) obtido para cada simulação.

$$
\text { RMSE }=\sqrt{\frac{\sum_{\mathrm{i}=1}^{\mathrm{n}}\left(\mathrm{y}_{\mathrm{i}}-\hat{\mathrm{y}_{1}}\right)^{\mathrm{a}}}{\mathrm{n}}}
$$

Onde $y_{i}$ representa o valor simulado; $\widehat{y_{1}} \mathrm{o}$ valor original e n o número total de dados utilizados para a simulação.

\section{Resultados e Discussão}

Na Figura 4 (a, b) são mostrados os valores de $\mathrm{R}^{2}$ para as 50 simulações realizadas para cada cenário analisado. $\mathrm{O}$ valor de $\mathrm{R}^{2}$ especifica a variação e compatibilidade entre os resultados previstos e os experimentais (Selvan, et al., 2018). Todos os valores são maiores que 0,99 , o que sugere que o modelo de RNA desenvolvido possui alta precisão e confiabilidade em estimar a demanda de biodiesel. 
Figura 4 - Valores de R das redes neurais artificiais do (a) B15 e do (b) B20.

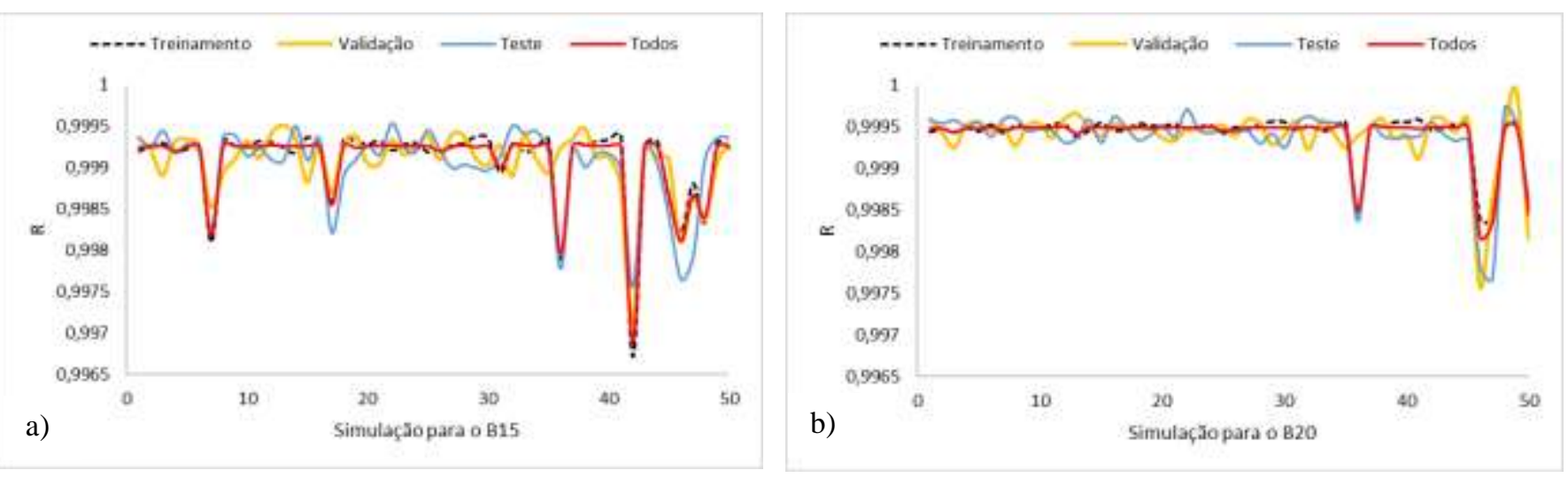

Fonte: Autores.

As melhores simulações foram determinadas usando a análise heurística dos valores do RMSE (Figura 5 (a, b)). Para o B15, a melhor simulação foi a décima primeira (RMSE = 1,1287\%). Para o B20, a trigésima sétima simulação proporcionou o menor RMSE (0,9882\%). O RMSE é usado para avaliar a proximidade das previsões com as observações. Quanto menor o RMSE mais precisa é a avaliação (Vastrad, 2013). Os baixos valores obtidos indicam que há uma boa concordância entres os valores experimentais e previstos.

Figura 5 - Análise heurística da rede neural artificial com base nos valores do RMSE para o (a) B15 e do (b) B20.
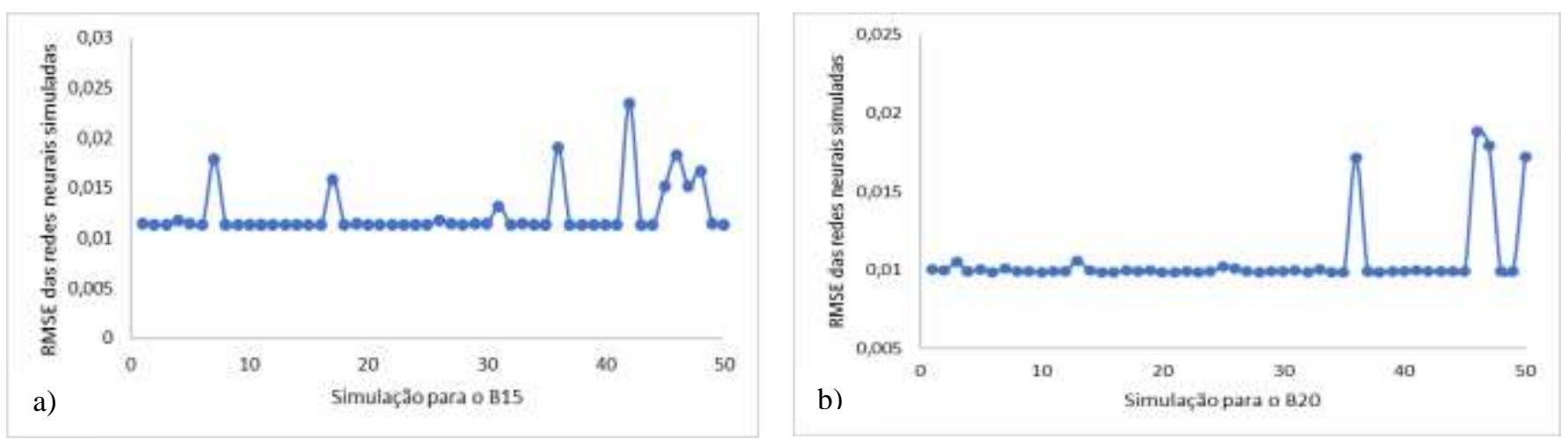

Fonte: Autores.

Todos os valores de RMSE para o B15 e B20 estão próximos de 2\%. Esse resultado é muito significativo, pois comprova a existência de pequenos erros, necessários para garantir que não haja overffiting na rede. Ou seja, a rede aprendeu bem o conjunto treinado e não perdeu o poder de generalização e previsão. Ao mesmo tempo, como o erro não foi muito grande, não houve o underffiting. Ou seja, a rede utilizada correspondeu ao problema e não falhou ao encontrar dependências significativas entre entradas e saídas (Đozić \& Urošević, 2019).

Os gráficos de regressão de saída (valores estimados) versus o desejado (valores experimentais) da $11^{\circ}$ simulação do B15 e $37^{\circ}$ para o B20 estão representados na Figura $6(a, b)$. Os valores dos coeficientes de correlação $\left(R^{2}\right)$ para o treinamento, validação, teste e conjuntos de dados completos para o B15 foram 0,99932, 0,99911, 0,99924 e 0,99926, respectivamente; e para o B20, 0,99949, 0,99950, 0,99950 e 0,99949, respectivamente. Todos os valores foram muito próximos de 1 indicando a significância do modelo usado, obtendo-se melhores resultados para o cenário B20. Os altos valores 
de $\mathrm{R}^{2}$ dos conjuntos de validação e teste de cada cenário demonstram as boas capacidades de estimativa e generalização do modelo de RNA, uma vez que os conjuntos de dados não faziam parte do conjunto de treinamento usado para o desenvolvimento do modelo (Betiku, et al., 2021). Além disso, para o ajuste perfeito os dados devem cair ao longo de uma linha de 45 graus em que as saídas da rede são iguais às metas (Thakur, et al., 2018). Como todos os pontos de dados estão muito próximos da linha de $45^{\circ}$, o modelo de RNA desenvolvido possui alta precisão na previsão da demanda de biodiesel.

Figura 6 - Coeficientes de correlação de treinamento, validação, teste e conjuntos de dados completos para o (a) B15 e do (b) B20.
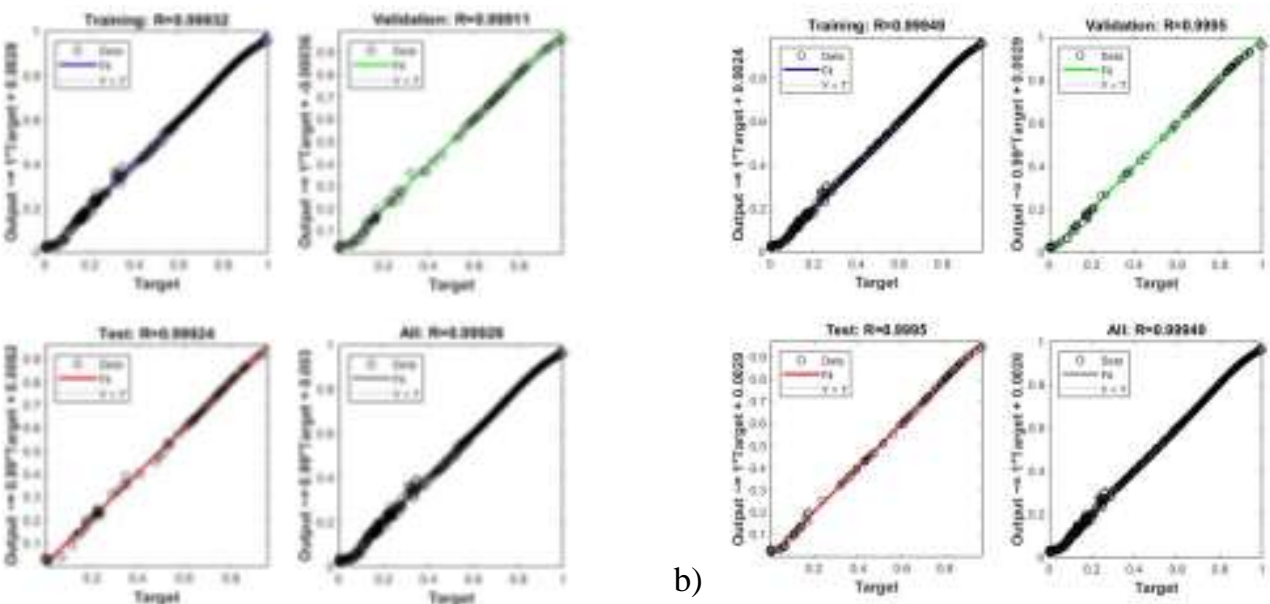

Fonte: Autores.

Os desempenhos das melhores redes nos treinamentos versus o número de épocas são mostrados na Figura 7 (a, b). Tem-se um alto valor de erro médio quadrático (MSE) nas primeiras épocas e, ao longo do treinamento, os pesos são ajustados para minimizar essa função, o que a diminui. Para o B15, o treinamento foi interrompido quando se atingiu o número máximo de iterações usadas nesta pesquisa (1000), onde obteve-se o menor MSE de 0,00017382. No B20, por sua vez, o menor MSE foi de 0,00011372 na época 472 . O motivo para a interrupção do treinamento é a verificação de validação. $O$ treinamento foi interrompido e os pesos dessa rede armazenados.

Figura 7 - Erro quadrático médio (MSE) em função das épocas durante o treinamento para o (a) B15 e do (b) B20.
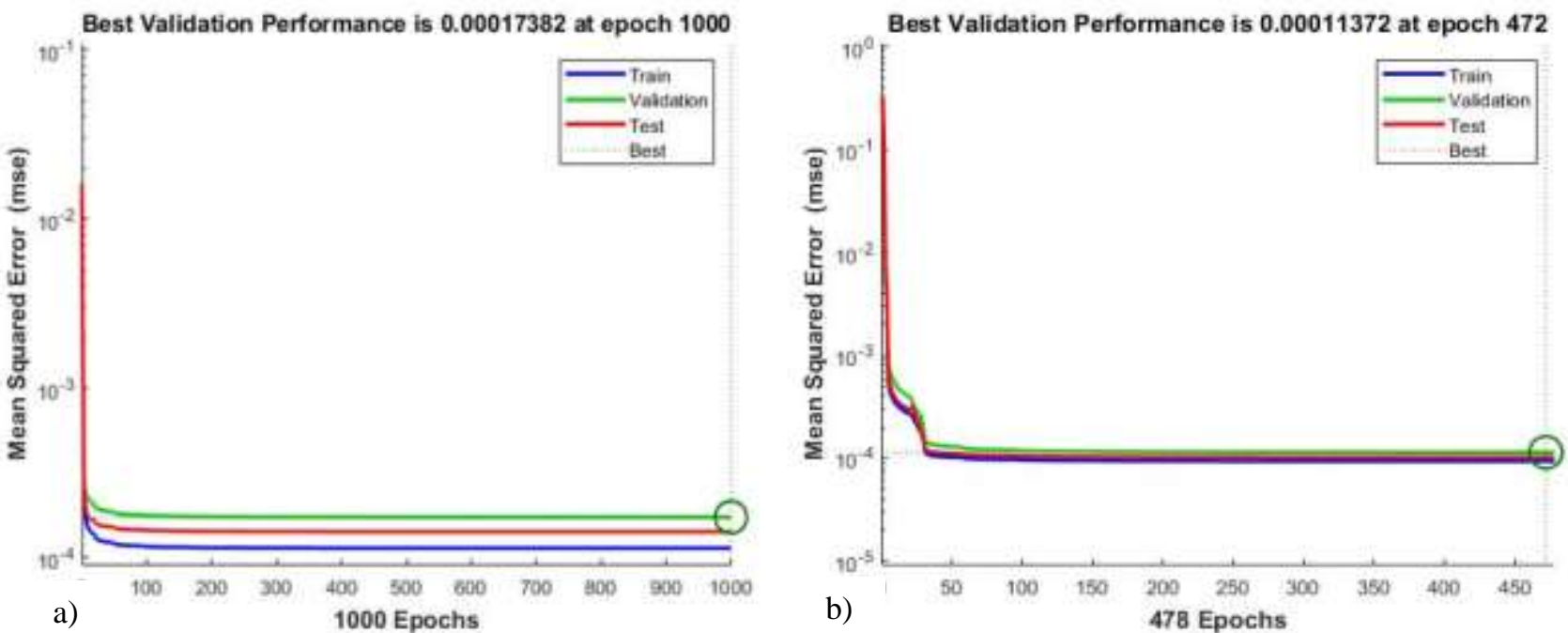

Fonte: Autores. 
A Figura 8 mostra os dados da ANP da produção de biodiesel entre 2005 a 2019, e compara com os resultados das simulações obtidos nos cenários do B15 e do B20. As redes seguem o comportamento dos valores medidos, com pequenas variações. Assim sendo, as redes para o B15 e o B20 conseguiram reproduzir completamente o sistema analisado de produção de biodiesel no Brasil.

Figura 8 - Dados fornecidos pela ANP e melhores simulados no período de 2005-2019 para o B15 e o B20.

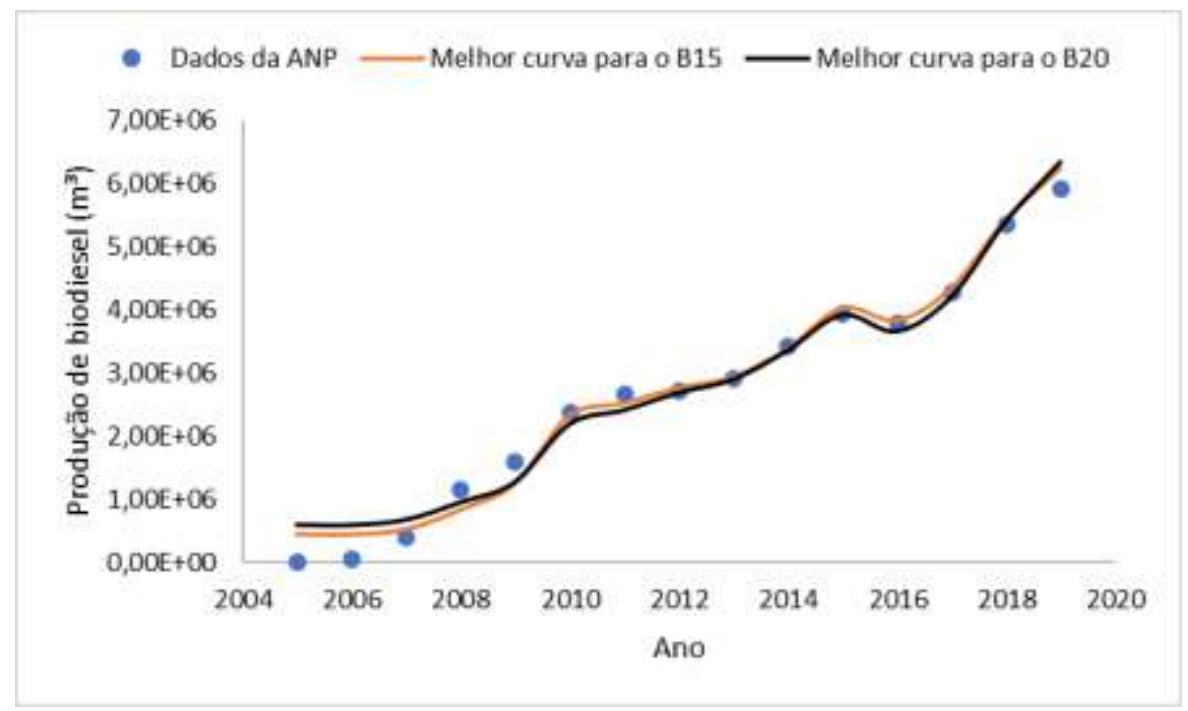

Fonte: Autores.

Em 2019, último período com dados disponíveis, a produção de biodiesel foi de 5,91E+06 m³. Para o cenário B15, a décima primeira simulação da RNA criada estimou que a demanda brasileira de biodiesel irá evoluir para $1,56 \mathrm{E}+07 \mathrm{~m}^{3}$ no ano de 2050. Com isso, teremos um crescimento de $150,63 \%$ em relação ao último ano vigente com uma taxa de crescimento anual de $3,01 \%$ (Figura 9).

Figura 9 - Estimativa da demanda de biodiesel no Brasil (2020-2050) para o B15 a partir das saídas obtidas pela décima primeira rede simulada desse cenário.

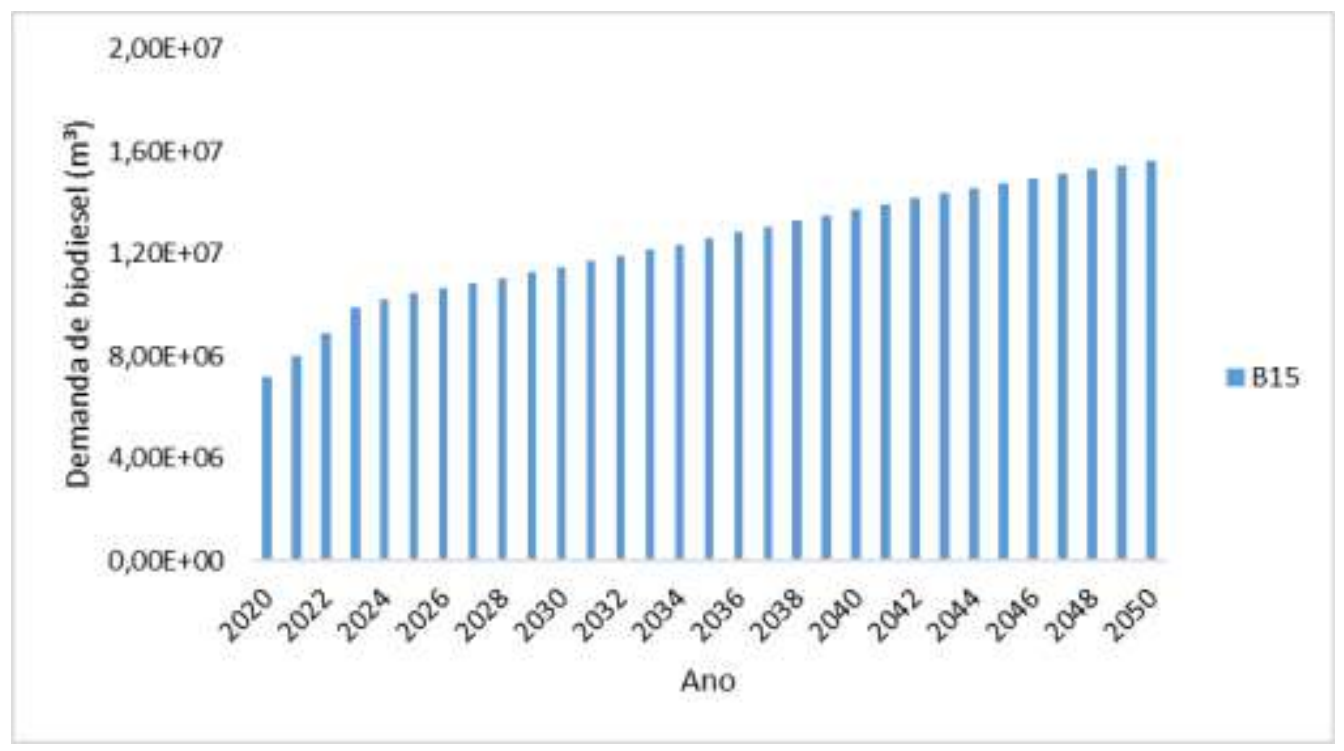

Fonte: Autores. 
Para o cenário B20, a trigésima sétima RNA estimou que a demanda brasileira de biodiesel chegará em 2,09E+07 m³ no ano de 2050, fornecendo um crescimento de $229,73 \%$ em relação ao ano de 2019 com uma taxa de crescimento anual de 3,92\% (Figura 10). Os maiores valores para o B20 devem-se ao fato desse cenário considerar um maior percentual de adição obrigatória de biodiesel ao diesel até o ano de 2050.

Figura 10 - Estimativa da demanda de biodiesel no Brasil (2020-2050) para o B20 a partir das saídas obtidas pela décima primeira rede simulada desse cenário.

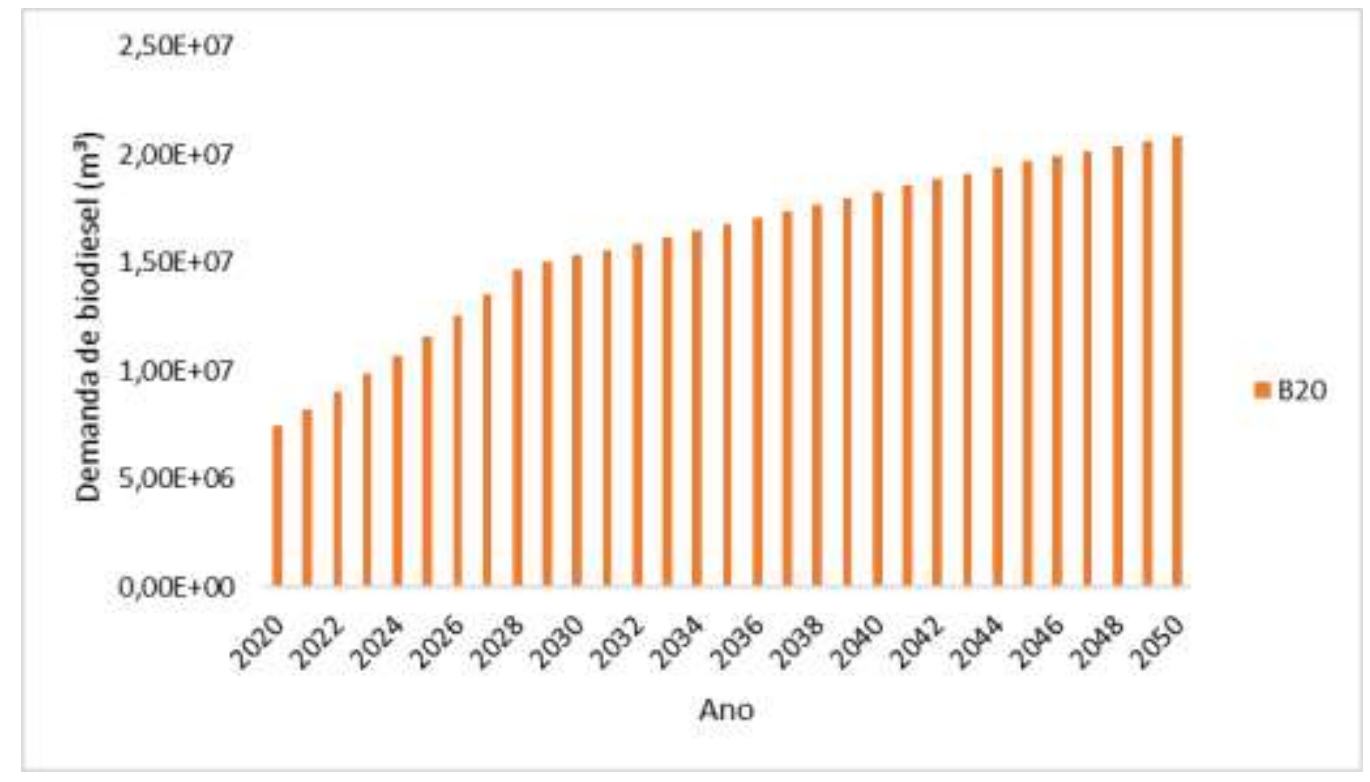

Fonte: Autores.

A crescente evolução da demanda de biodiesel nos cenários analisados deve-se especialmente ao incentivo governamental para adição de biodiesel ao diesel. $\mathrm{O}$ aumento do percentual obrigatório nos últimos anos garante uma participação cada vez maior desse biocombustível na matriz energética brasileira, além de dar sustentação à geração de emprego e renda no campo.

O B15 já é uma realidade no país visando atingir as metas de redução de emissões firmadas no Acordo do Clima de Paris, no qual a Contribuição Nacionalmente Determinada (NDC) do Brasil comprometeu-se a reduzir as emissões de gases de efeito estufa em 37\% abaixo dos níveis de 2005, em 2025, bem como alcançar uma participação estimada de 45\% de energias renováveis na composição da matriz energética em 2030 (Ministério do Meio Ambiente, 2020). Além disso, o Brasil tem plenas condições de implementar uma evolução anual de 1\% de biodiesel ao diesel até atingir o B20 em 2028, como estabelecido pela PL 528/2020, já em tramitação.

Tendo o B20 como mistura mínima obrigatória em 2030, o Brasil desfrutará de benefícios como: o biodiesel representará próximo de 9\% da Matriz de Combustíveis Brasileira; o biodiesel reduzirá a necessidade de importação de diesel e evitará dispêndios em 2030 da ordem de US\$ 4 bilhões, a preços atuais; será evitada a emissão de aproximadamente 34 milhões de toneladas de $\mathrm{CO}_{2}$ equivalente por ano, em 2030, o que corresponde a 250 milhões de árvores plantadas por ano. Com isso, o biodiesel brasileiro participará do esforço para evitar o aumento da temperatura global (União Brasileira do biodiesel e bioquerosene, 2016).

Os resultados do B15 estão alinhados com a última projeção de demanda de biodiesel feita pelo Ministério de Minas e Energia (MME) e publicado através do Plano Decenal de Expansão de energia de 2029, com a estimativa até o ano de 2030 (Ministério de Minas e Energia, 2020). A diferença em relação ao B20 está no fato de que esse cenário é uma projeção 
considerando uma PL que está em tramitação, enquanto o B15 já está definido por lei (Figura 11). A concordância dos resultados obtidos pela rede neural com as últimas estimativas do governo brasileiro reforça a qualidade e eficácia do modelo utilizado em prever a demanda de biodiesel no Brasil.

Figura 11 - Comparação das estimativas da demanda de biodiesel feita pelo MME com as obtidas do B15 e B20 pela RNA.

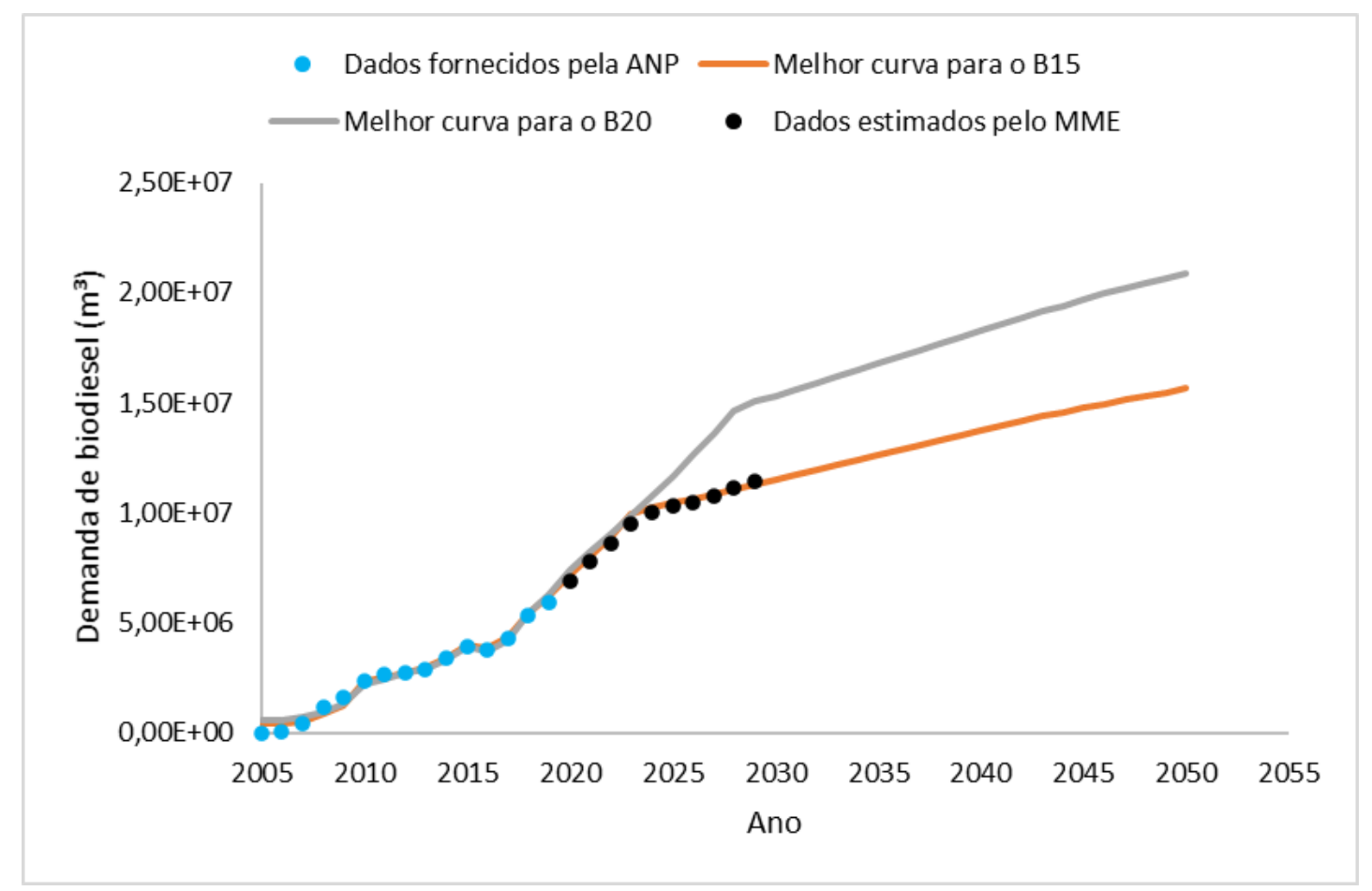

Fonte: Autores.

\section{Conclusão}

Este estudo trata do uso de redes neurais artificiais e de um modelo não-paramétrico de previsão de demanda com sazonalidade e tendência dos dados para estimar com eficiência a demanda de biodiesel no Brasil até o ano de 2050. Foi utilizado o banco de dados da ANP do período de 2005 a 2019 para duas variáveis independentes utilizadas: a porcentagem obrigatória de adição do biodiesel ao diesel e as vendas de diesel B.

Foram modeladas 100 redes do tipo perceptron multicamadas com retropropagação do erro para dois cenários do biodiesel brasileiro: 50 redes para 15\% de porcentagem obrigatória do biodiesel ao diesel até o ano de 2023 e manutenção até 2050 (B15); 50 redes para 20\% de porcentagem obrigatória do biodiesel ao diesel até o ano de 2028 e manutenção até o ano de 2050 (B20). Todos os valores de $\mathrm{R}^{2}$ maiores que 0,99 e RMSE menores que $2 \%$ comprovam que o modelo de RNA desenvolvido possui alta precisão em prever a demanda de biodiesel. A melhor rede para cada cenário foi determinada por análise heurística do RMSE.

Os resultados das melhores RNA's simuladas mostraram, para o Brasil, um crescimento de 2019-2050 de 150,63\% para o B15 e 229,73\% para o B20, com uma taxa de crescimento anual de 3,01\% para o primeiro e 3,92\% para o segundo. Ambos cenários de aumento de demanda são comprovados pelo aumento gradual da porcentagem obrigatória do biodiesel ao diesel.

A alta capacidade do modelo de RNA associado a um modelo não-paramétrico de previsão em estimar a demanda de biodiesel mostra-se de grande utilidade, uma vez que permite conhecer o quanto um país pode crescer no que diz respeito ao uso de uma fonte alternativa aos combustíveis fósseis. Para o Brasil, os resultados crescentes da demanda de biodiesel 
comprovam a busca do país por um combustível não-tóxico, biodegradável e renovável na sua matriz energética.

Para trabalhos futuros, sugerimos que os novos dados divulgados mensalmente pela ANP sejam utilizados para atualização do modelo. Além disso, recomendamos que a demanda por biodiesel seja avaliada em pesquisas futuras que considerem outros cenários possíveis de consumo de diesel.

\section{Referências}

Acheampong, A. O., \& Boateng, E. B. (2019). Modelling carbon emission intensity: Application of artificial neural network. Journal of Cleaner Production, 225, 833-856. doi: 10.1016/j.jclepro.2019.03.352

ANP - Agência Nacional de Petróleo, Gás Natural e Biocombustível. (2020). Biodiesel. Retrieved July 10, 2020, from http://www.anp.gov.br/biocombustiveis/biodiesel

Betiku, E., Osunleke, A. S., Odude, V. O., Bamimore, A., Oladipo, B., Okeleye, A. A., \& Ishola, N. B. (2021). Performance evaluation of adaptive neurofuzzy inference system, artificial neural network and response surface methodology in modeling biodiesel synthesis from palm kernel oil by transesterification. Biofuels, 12(3), 339-354. doi: 10.1080/17597269.2018.1472980

Brahimi, T., Alhebshi, F., Alnabilsi, H., Bensenouci, A., \& Rahman, M. (2019). Prediction of Wind Speed Distribution Using Artificial Neural Network: The Case of Saudi Arabia. Procedia Computer Science, 163, 41-48. doi: 10.1016/j.procs.2019.12.084.

Carmo, B. B. T., Pontes, H. L. J., Albertin, M. R., Neto, J. F. B., \& da Silva Dutra, N. G. (2009). Avaliação da demanda por biodiesel em função de um modelo de previsão de demanda por diesel. Revista Produção Online, 9(3),511-535.

Chidambaranathan, B., Gopinath, S., Aravindraj, R., Devaraj, A., Krishnan, S. G., \& Jeevaananthan, J. K. S. (2020). The production of biodiesel from castor oil as a potential feedstock and its usage in compression ignition Engine: A comprehensive review. Materials Today: Proceedings, 33, 84-92. doi: 10.1016/j.matpr.2020.03.205

CNPE - Conselho Nacional de Política Energética. (2018). Resolução CNPE $\mathrm{n}^{\circ}$ 16, de 29 de outubro de 2018. Retrieved July 10, 2020, from https://www.gov.br/mme/pt-br/assuntos/conselhos-e-comites/cnpe/resolucoes-do-cnpe/arquivos/2018/resolucao_16_cnpe_29-10-18.pdf

Đozić, D. J., \& Urošević, B. D. G. (2019). Application of artificial neural networks for testing long-term energy policy targets. Energy, 174, 488-496. doi: 10.1016/j.energy.2019.02.191

Ebrahimabadi, A., Azimipour, M., \& Bahreini, A. (2015). Prediction of roadheaders' performance using artificial neural network approaches (MLP and KOSFM). Journal of Rock Mechanics and Geotechnical Engineering, 7(5), 573-583. doi: 10.1016/j.jrmge.2015.06.008

Ekonomou, L. (2010). Greek long-term energy consumption prediction using artificial neural networks. Energy, 35(2), 512-517. doi: 10.1016/j.energy.2009.10.018

Farobie, O., Hasanah, N., \& Matsumura, Y. (2015). Artificial neural network modeling to predict biodiesel production in supercritical methanol and ethanol using spiral reactor. Procedia environmental sciences, 28, 214-223. doi: 10.1016/j.proenv.2015.07.028

Gupta, N., \& Nigam, S. (2020). Crude Oil Price Prediction using Articial Neural Network. Procedia Computer Science. 170, 642-647. doi:10.1016/j.procs.2020.03.136.

Jayalakshmi, T., \& Santhakumaran, A. (2011). Statistical normalization and back propagation for classification. International Journal of Computer Theory and Engineering, 3(1), 1793-8201. Retrieved from http://www.ijcte.org/papers/288-L052.pdf

Karunathilake, S. L., \& Nagahamulla, H. R. (2017, September). Artificial neural networks for daily electricity demand prediction of Sri Lanka. In 2017 Seventeenth International Conference on Advances in ICT for Emerging Regions (ICTer) (pp. 1-6). IEEE.

Katsatos, A. L., \& Moustris, K. P. (2019). Application of Artificial Neuron Networks as energy consumption forecasting tool in the building of Regulatory Authority of Energy, Athens, Greece. Energy Procedia, 157, 851-861. doi: 10.1016/j.egypro.2018.11.251

Kochak, A., \& Sharma, S. (2015). Demand forecasting using neural network for supply chain management. International journal of mechanical engineering and robotics research, 4(1), 96-104. doi: 10.18178/ijmerr.

Ling, Y., Yue, Q., Chai, C., Shan, Q., Hei, D., \& Jia, W. (2020). Nuclear accident source term estimation using Kernel Principal Component Analysis, Particle Swarm Optimization, and Backpropagation Neural Networks. Annals of Nuclear Energy, 136, 107031. doi: 10.1016/j.anucene.2019.107031

Ministério de Minas e Energia, Empresa de Pesquisa Energética - MME/EPE. (2020). Plano Decenal de Expansão de Energia 2029. Retrieved July 03, 2020, from https://www.epe.gov.br/pt/publicacoes-dados-abertos/publicacoes/plano-decenal-de-expansao-de-energia-2029

Ministério do Meio Ambiente. (2020). Acordo de Paris. Retrieved July 10, 2020, from https://www.mma.gov.br/clima/convencao-das-nacoes-unidas/acordode-paris

Pereira, A. S., Shitsuka, D. M., Parreira, F. J., \& Shitsuka, R. (2018). Metodologia da pesquisa científica. Santa Maria: UFSM, NTE.

Queiroz, A. A., \& Cavalheiro, D. (2003). Método de previsão de demanda e detecção de sazonalidade para o planejamento da produção de indústrias de alimentos. Anais do Encontro Nacional de Engenharia de Produção, 23.

Rajakarunakaran, S., Venkumar, P., Devaraj, D., \& Rao, K. S. P. (2008). Artificial neural network approach for fault detection in rotary system. Applied Soft Computing, 8(1), 740-748. doi: 10.1016/j.asoc.2007.06.002 
Research, Society and Development, v. 10, n. 5, e17410513381, 2021

(CC BY 4.0) | ISSN 2525-3409 | DOI: http://dx.doi.org/10.33448/rsd-v10i5.13381

Selvan, S. S., Pandian, P. S., Subathira, A., \& Saravanan, S. (2018). Artificial neural network modeling-coupled genetic algorithm optimization of supercritical methanol transesterification of Aegle marmelos oil to biodiesel. Biofuels, 1-9. doi: 10.1080/17597269.2018.1542567

Singh, D., Sharma, D., Soni, S. L., Sharma, S., Sharma, P. K., \& Jhalani, A. (2020). A review on feedstocks, production processes, and yield for different generations of biodiesel. Fuel, 262, 116553. doi:10.1016/j.fuel.2019.116553.

Sivamani, S., Selvakumar, S., Rajendran, K., \& Muthusamy, S. (2019). Artificial neural network-genetic algorithm-based optimization of biodiesel production from Simarouba glauca. Biofuels, 10(3), 393-401. doi: 10.1080/17597269.2018.1432267

Thakur, A. K., Mer, K. K. S., \& Kaviti, A. (2018). An artificial neural network approach to predict the performance and exhau st emissions of a gasoline engine using ethanol-gasoline blended fuels. Biofuels, 9(3), 379-393.doi: 10.1080/17597269.2016.1271630

Tubino, D. F. (2007). Planejamento e controle da produção: teoria e prática. São Paulo: Atlas.

Turp, S. M., Eren, B., \& Ates, A. (2011). Prediction of adsorption efficiency for the removal of nickel (II) ions by zeolite using artificial neural network (ANN) approach. Fresenius Environmental Bulletin,20(12), 3158-3165. Retrieved from https://d1wqtxts1xzle7.cloudfront.net/30548310/02-FEBPrediction_of_adsorption_efficiency_for_the_removal_of.pdf?1360286886=\&response-content-

disposition=inline\%3B+filename\%3DPREDICTION_OF_ADSORPTION_EFFICIENCY_FOR.pdf\&Expires=1618498882\&Signature=LbccMwk31LWMu4 GcTriv6aoz E1 LYk9uddxkeqQJBigkGd3YhuK46-

n1WMxg1HQn0TBIv7VdCqwLr9ecbNEmHfYAfjmhYbSV2M5mwaOB1zP43UcFcDpGBYM2NeEEhgyvA QFKfmmW2vOyut5xFIs dibp Eeq5u7kP1HqI cYOL5FpRg0 Sz5LB5aOO WG-

ejZTEQnbXN8pL0UsamqEvIKsz3QrQtKz49H1ykRmFGrMRRkY3U9h5EAnm V311fdIfmc1TtKxKj5BakgLAeo2Qd013Ip65wDmHK6o6C4 VcX0UYd5p wk4MOSb4L01Suu0sOV-BAJ0WrVvPKRqnvSumg__\&Key-Pair-Id=APKAJLOHF5GGSLRBV4ZA

União Brasileira do biodiesel e bioquerosene - Ubrabio. (2016). Energia para combater as mudanças climáticas. Biodiesel em foco; 9-17. Retrieved July 5, 2020, from https://issuu.com/ubrabio/docs/biodiesel_em_foco_-_ed_07-2016-web/17

Vastrad, C. (2013). Performance analysis of neural network models for oxazolines and oxazoles derivatives descriptor dataset. International Journal of Information Sciences and Techniques (IJIST), 3(6). doi: 10.5121/ijist.2013.3601

Zhang, G., Patuwo, B. E., \& Hu, M. Y. (1998). Forecasting with artificial neural networks: The state of the art. International journal of forecasting, 14(1), 3562 . 